\title{
Pitiose eqüina no Pantanal brasileiro: aspectos clínico- patológicos de casos típicos e atípicos ${ }^{1}$
}

\author{
Adriana B. Monteiro Leal ${ }^{2}$, Alexandre T. Leal ${ }^{2}$, Janio M. Santurio ${ }^{3}$, Glaucia D. \\ Kommers $^{4}$ e João B. Catto ${ }^{5}$
}

\begin{abstract}
Leal A.B.M., Leal A.T., Santurio J.M., Kommers G.D. \& Catto J.B. 2001. [Equine pythiosis in the Brazilian Pantanal region: Clinical and pathological findings of typical and atypical cases] Pitiose equiina no Pantanal brasileiro: aspectos clínico-patológicos de casos típicos e atípicos. Pesquisa Veterinária Brasileira 21(4):151-156. Laboratório de Pesquisas Micológicas, Depto Microbiologia e Parasitologia, Universidade Federal de Santa Maria, 97105900 Santa Maria, RS, Brazil. E-mail: santurio@ccr.ufsm.br

Equine pythiosis is an endemic disease of horses and causes significant economic losses to equine breeding in the Brazilian Pantanal. This article describes 16 cases of subcutaneous pythiosis in horses from that region. The clinical cases were divided in typical (11) and atypical (5), according to the clinical features and duration of the disease. The clinical diagnosis was confirmed by detection of specific antibodies by ELISA, isolation of the agent and histopathology. The duration of the disease varied from 1 to 6 months in the typical cases and was over 12 months in the atypical ones. The lesions in the typical cases were characterized by subcutaneous ulcerated granulomas with abundant serosanguineous secretion and itching. The atypical cases presented subcutaneous lesions characterized by large, circumscribed tumorous masses covered by a dark non ulcerated skin, associated with little or no secretion. These lesions showed a well organized aspect, were sometimes pedunculate and the animals showed a good body condition. Histologically, the typical cases were characterized by granulation tissue with abundant eosinophils; whereas the atypical cases presented pseudoepitheliomatous hyperplasia of the epidermis and eosinophilic infiltrate. The complete description of the clinical and histopathological features and possible factors responsible for differences between the two clinical forms are presented and discussed.
\end{abstract}

INDEX TERMS: Pythiosis, Pythium insidiosum, equine, granuloma, Pantanal.

RESUMO.- A pitiose eqüina é doença endêmica no Pantanal Brasileiro e causa prejuízos significativos a equiinocultura. Neste trabalho são relatados 16 casos de pitiose subcutânea em eqüinos no Pantanal Sul-Matogrossense, que foram divididos em onze casos típicos e cinco casos atípicos, de acordo

\footnotetext{
${ }^{1}$ Aceito para publicação em 17 de outubro de 2001.

Trabalho realizado com suporte financeiro do PRODETAB.

${ }^{2}$ Laboratório de Pesquisas Micológicas (LAPEMI), Depto Microbiologia e Parasitologia, Centro de Ciências da Saúde (CCS) e Centro de Ciências Rurais (CCR), Universidade Federal de Santa Maria (UFSM).

${ }^{3}$ LAPEMI e Depto Medicina Veterinária Preventiva (DMVP), UFSM. Autor para correspondência: DMVP / CCR / UFSM, 97105-900 Santa Maria, RS. Fone (055) 220-8689. E-mail: santurio@ccr.ufsm.br

${ }^{4}$ Depto de Patologia, CCS, UFSM.

${ }^{5}$ Embrapa Gado de Corte, Campo Grande, MS.
}

com o quadro clínico e o tempo de duração das lesões. 0 diagnóstico foi confirmado pela deteç̧ão de anticorpos específicos pelo teste ELISA, isolamento do agente e histopatológico. A duração da doença variou entre 1 e 6 meses nos casos típicos e superior a 12 meses nos casos atípicos. As lesões dos casos típicos caracterizavam-se por granulomas subcutâneos, ulcerados, com abundante secreção serossanguinolenta e prurido. Nos casos atípicos foram observadas lesões subcutâneas caracterizadas por grandes massas "tumorais" circunscritas, recobertas por pele escura, sem ulcerações e com pouca secreção. Os animais estavam em bom estado nutricional e as lesões apresentavam-se de aspecto organizado, às vezes pedunculadas. Histologicamente, foi observado tecido de granulação com muitos eosinófilos nos casos típicos, enquanto os atípicos, se caracterizaram por hiperplasia pseudo-epiteliomatosa da epiderme e infiltrado eosinofílico. As características clínicas e histopato- 
lógicas completas das duas formas clínicas e os possíveis fatores responsáveis pelas diferenças entre as duas formas são apresentados e discutidos.

TERMOS DE INDEXAÇÃO: Pitiose, Pythium insidiosum, granuloma, eqüino, Pantanal.

\section{INTRODUÇÃO}

A pitiose em eqüinos é uma doença ulcerativa, proliferativa na pele e tecido subcutâneo causada por Pythium insidiosum (Chaffin et al. 1995), um "fungo" zoospórico, do Reino Stramenopila, filo Oomycota, família Pythiaceae, encontrado principalmente em regiões pantanosas com temperaturas médias superiores a $25^{\circ} \mathrm{C}$ (Alexopoulos et al. 1996). $\mathrm{O}$ agente está presente em águas estagnadas e utiliza plantas aquáticas em seu ciclo biológico, que inclui reprodução assexuada e sexuada, produzindo zoosporos biflagelados, a forma infectante (Mendoza \& Prendas 1988). A enfermidade tem evolução rápida e difícil tratamento. $O$ sucesso do tratamento é influenciado pelo tamanho, tempo, local das lesões e, possivelmente, pela idade e estado fisiológico do animal (Miller \& Campbell 1982, Mendoza et al. 1996).

Nos eqüinos, as lesões afetam principalmente a pele e $o$ tecido subcutâneo dos membros, cabeça e região tóraco-abdominal (Mendoza et al. 1996). Além de lesões cutâneas, os equiinos podem apresentar distúrbios gastrointestinais, provocados por massas tumorais que podem levar a distensões, impactações e cólicas intestinais (Allison \& Gillis 1990, Morton et al. 1991). Lesões com envolvimento ósseo tem sido observadas em ossos adjacentes a lesões subcutâneas nos membros (Alfaro \& Mendoza 1990, Eaton 1993). Fischer et al. (1994) relataram onze casos de pitiose gastrointestinal em cães, caracterizada por inflamação granulomatosa acentuada no trato alimentar. Dykstra et al. (1999) descreveram quinze casos de pitiose subcutânea em cães, caracterizados por lesões crônicas, ulceradas e com múltiplos nódulos. Em bovinos, a doença apresenta-se como granulomas multifocais discretos (Miller et al. 1985, Santurio et al. 1998). Bissonette et al. (1991), relataram a doença em um felino com lesões na porção retrobulbar e nasal, causando destruição óssea. A pitiose em humanos não tem sido descrita nas mesmas áreas endêmicas para equiinos e ocorre com mais frequiência na Tailândia. As lesões podem se apresentar de três formas: cutâneas e subcutâneas, ceratites ou infecção sistêmica, em muitos casos associada a gangrena e arterite crônica (Imwidthaya 1994).

O primeiro relato de pitiose no Brasil foi feito no Rio Grande do Sul por Santos \& Londero (1974), que a descreveram como quatro casos de zigomicose eqüina. No Pantanal brasileiro, onde a doença tem maior ocorrência, é conhecida como "ferida-brava" ou "ferida-da-moda" (Carvalho et al. 1984). Meireles et al. (1993), relataram cinco casos de pitiose cutânea em eqüinos na região pantanosa de Capão do Leão, Rio Grande do Sul. Desses, dois animais apresentavam lesões na região abdominal, dois na porção distal dos membros e um na narina. Todas as lesões apresentavam aspecto granulomatoso com múltiplas ulcerações, bordas irregulares e contínua descarga mucosa. Tabosa et al. (1999), relataram trinta e cinco casos de pitiose em eqüinos e três em muares no Estado da Paraíba. Todos os animais apresentaram lesão granulomatosas e ulceradas recobertas por secreção serossanguinolenta com presença de grandes concreções semelhantes a corais ("kunkers"). Os "kunkers" são massas necróticas de coloração branco-amarelada, com diâmetro entre 2 e $10 \mathrm{~mm}$, de forma irregular e ramificada e, encontram-se no interior do granuloma, dentro de sinus formados ao longo do seu trajeto (Leal et al. 2001). No Pantanal brasileiro os "kunkers" são popularmente denominados de pedras. Microscopicamente os "kunkers" apresentam-se como coágulos eosinofílicos, compostos de hifas, colágeno, arteríolas e células inflamatórias, especialmente eosinófilos. A área em torno do coágulo é composta por um exsudato inflamatório espesso de neutrófilos e eosinófilos (Miller \& Campbell 1984, Chaffin et al. 1995). Outros casos de pitiose em eqüinos, no Brasil, foram relatados por Sanavria et al. (2000), e referem-se a cinco animais da raça Mangalarga Marchador com lesões nos membros, abdômen, dorso e face. Macroscopicamente, essas lesões foram caracterizadas com tumorações esponjosas com bordas ulceradas e $P$. insidiosum foi isolado das biópsias.

Este trabalho tem por objetivo relatar 16 casos de pitiose típica e atípica em eqüinos na região do Pantanal Sul-Matogrossense, onde a doença é endêmica.

\section{MATERIAL E MÉTODOS}

Dezesseis eqüinos sem raça definida (SRD), de ambos os sexos e com idades entre um e oito anos, foram observados por aproximadamente quatro meses. Os animais eram oriundos de fazendas da região do Pantanal da Nhecolândia (Corumbá, MS) e apresentavam lesões cutâneas suspeitas de pitiose. As lesões caracterizavam-se pela presença de tumorações cutâneas ou subcutâneas localizadas nos membros, na face e na porção ventral da parede tóraco-abdominal. Os animais foram divididos em dois grupos (I e II), de acordo com as características clínicas e o tempo de duração das lesões.

Após a avaliação clínica e formação dos grupos, foi colhido soro e realizada biópsia para confirmação do diagnóstico em cada um dos equiinos. As amostras de soro foram testadas para anticorpos específicos pelo ensaio imunoenzimático em fase sólida indireta (ELISA). O material de biópsia contendo "kunkers", foi dividido em duas porções, uma para exame histológico e outra para o isolamento do agente. Para o isolamento, fragmentos de tecidos obtidos na biópsia foram lavados em água estéril, seccionados em pequenos fragmentos ( $3 \mathrm{~mm}$ de espessura) e lavados em água estéril contendo estreptomicina, 40.000 UI e penicilina 20.000 UI (Shipton et al. 1982). Em seguida, os fragmentos de tecido e "kunkers" foram semeados em tubos com tampa de rosca contendo Agar Sabouraud Dextrose (ASD) ou caldo Sabouraud e incubados a $37^{\circ} \mathrm{C}$ por 48 horas. A identificação do fungo baseou-se nas características macroscópicas e microscópicas de Pythium insidiosum, além da indução de zoosporogênese, que permite a identificação dos zoosporos móveis (Shipton et al. 1982, Mendoza \& Prendas 1988). Os fragmentos de biópsia destinados à histopatologia foram fixados em solução de formol a $10 \%$ e processados pelos métodos de rotina para as colorações de hematoxilina-eosina e Gömori (GMS). 


\section{RESULTADOS}

A confirmação do diagnóstico foi obtida pelo teste ELISA e isolamento do agente. No exame sorológico todos os eqüinos testados foram positivos para a presença de IgG anti Pythium insidiosum, confirmando a suspeita clínica. No isolamento, observou-se o crescimento de colônias brancas com crescimento radial, micélio aéreo curto e hifas enraizadas no meio de cultura. Nos tubos contendo caldo Sabouraud observouse um crescimento algodonoso de cor esbranquiçada, emergindo dos "kunkers" e dos tecidos. Ao exame microscópico em aumento de 100 e 400x observaram-se hifas raramente septadas, com ramificações laterais freqüientemente perpendiculares, sem estruturas reprodutivas e extremidades arredondadas. Essas características associados a indução de zoosporogênese permitiram a identificação de $P$. insidiosum. Em sete amostras não foi possível $o$ isolamento do agente devido, principalmente, a contaminações secundárias por outros fungos ambientais, leveduras e bactérias.

A formação de dois grupos baseou-se nas características clínicas das lesões cutâneas/subcutâneas e no tempo de duração das lesões (Quadro 1). As principais diferenças observadas entre os grupos são resumidas no Quadro 2. No Grupo I (casos típicos) foram incluídos onze animais com duração da doença entre 1 e 6 meses. Esses animais apresentaram lesões subcutâneas de evolução progressiva, abundante tecido de granulação, ulceração, secreção serossanguinolenta à mucossanguinolenta e presença de "kunkers". Prurido intenso e claudicação nos animais com lesões nos membros também foram observados. Alguns animais coçavam intensamente a ferida, dilacerando a mesma, as vezes causando sangramento profuso (Fig. 1). Os casos do Grupo I evoluíram rapidamente, com aumento das lesões associado a emagrecimento e debilitação geral dos animais, culminando com a morte de

Quadro 1. Características clínicas e métodos utilizados no diagnóstico de pitiose em eqüinos

\begin{tabular}{|c|c|c|c|c|c|c|c|c|c|}
\hline \multirow{2}{*}{$\begin{array}{l}\text { Grupo / no } \\
\text { do animal }\end{array}$} & \multirow{2}{*}{$\begin{array}{l}\text { Idade } \\
\text { (anos) }\end{array}$} & \multirow[t]{2}{*}{ Sexo } & \multicolumn{4}{|c|}{ Características das lesões } & \multicolumn{3}{|r|}{ Diagnóstico } \\
\hline & & & $\begin{array}{c}\text { Localização } \\
\text { anatômica }\end{array}$ & $\begin{array}{c}\text { Dimensão } \\
(\mathrm{cm})\end{array}$ & $\begin{array}{r}\text { Duração } \\
\text { (meses) }\end{array}$ & Macroscopia da lesão & ELISA & Cultura & Histopatologia dos "kunkers" \\
\hline $\mathrm{I} / 08$ & 6 & $\mathrm{~F}$ & $\begin{array}{l}\text { MAE }^{\mathrm{a}} \\
\text { MAD } \\
\text { MPE }\end{array}$ & $\begin{array}{l}4 \times 8.5 \\
5.5 \times 8 \\
9.5 \times 9\end{array}$ & 4 & $\begin{array}{l}\text { Ulceradas com secreção } \\
\text { serossanguinolenta }\end{array}$ & Pos. & Pos. & $\begin{array}{l}\text { Necrose eosinofílica com hifas } \\
\text { irregulares e ramificadas }\end{array}$ \\
\hline I / 09 & 1,5 & $\mathrm{~F}$ & MPD & $14 \times 14$ & 1 & $\begin{array}{l}\text { Ulcerada com secreção } \\
\text { mucossanguinolenta }\end{array}$ & Pos. & Pos. & Não realizado \\
\hline $\mathrm{I} / 10$ & 9 & $\mathrm{~F}^{\mathrm{b}}$ & $\begin{array}{l}\text { MAD } \\
\text { MPE }\end{array}$ & $\begin{array}{l}24 \times 16 \\
22 \times 27\end{array}$ & 3 & $\begin{array}{l}\text { Ulceradas com secreção } \\
\text { mucossanguinolenta }\end{array}$ & Pos. & Pos. & $\begin{array}{l}\text { Necrose eosinofílica com hifas } \\
\text { irregulares e ramificadas }\end{array}$ \\
\hline $\mathrm{I} / 12$ & 6 & $\mathrm{~F}$ & MPD & $27 \times 19$ & 3 & $\begin{array}{l}\text { Ulcerada com secreção } \\
\text { mucopurulenta }\end{array}$ & Pos. & Neg. & $\begin{array}{l}\text { Necrose eosinofílica com hifas } \\
\text { irregulares e ramificadas }\end{array}$ \\
\hline $\mathrm{I} / 13$ & 3 meses & $\mathrm{F}$ & MAE & $17 \times 11$ & 2 & $\begin{array}{l}\text { Ulcerada com secreção } \\
\text { serossanguinolenta }\end{array}$ & Pos. & Pos. & $\begin{array}{l}\text { Necrose eosinofílica com hifas } \\
\text { irregulares e ramificadas }\end{array}$ \\
\hline $\mathrm{I} / 14$ & 8 & $\mathrm{~F}$ & MPD & $6 \times 4$ & 2 & $\begin{array}{l}\text { Ulcerada com secreção } \\
\text { serossanguinolenta }\end{array}$ & Pos. & Neg. & Biópsia sem "kunkers" \\
\hline $\mathrm{I} / 15$ & 5 & $\mathrm{~F}$ & MPE & $3 \times 5$ & 3 & $\begin{array}{l}\text { Ulcerada, sem secreção } \\
\text { irregulares e ramificadas }\end{array}$ & Pos. & Neg. & Necrose eosinofílica com hifas \\
\hline I / 16 & 4 & M & MAE & $10 \times 6$ & 1 & $\begin{array}{l}\text { Parcialmente ulcerada com } \\
\text { secreção serossanguinolenta }\end{array}$ & Pos. & Neg. & Não realizado \\
\hline I / 20 & 1 & $\mathrm{~F}$ & MPE & $8 \times 10$ & 2 & $\begin{array}{l}\text { Ulcerada com secreção } \\
\text { mucossanguinolenta }\end{array}$ & Pos. & Pos. & $\begin{array}{l}\text { Necrose eosinofílica com hifas } \\
\text { irregulares e ramificadas }\end{array}$ \\
\hline $\mathrm{I} / 21$ & 8 & $\mathrm{~F}$ & MPE & $15 \times 15$ & 2 & $\begin{array}{l}\text { Ulcerada com secreção } \\
\text { serossanguinolenta }\end{array}$ & Pos. & Neg. & $\begin{array}{l}\text { Necrose eosinofílica com hifas } \\
\text { irregulares e ramificadas }\end{array}$ \\
\hline I / 24 & 4 & M & Prepúcio & $24 \times 23$ & 1 & $\begin{array}{l}\text { Ulcerada com secreção } \\
\text { serossanguinolenta }\end{array}$ & Pos. & Neg. & Não realizado \\
\hline II / 01 & 8 & M & $\begin{array}{l}\text { Face medial } \\
\text { do MPE }\end{array}$ & $21 \times 49$ & 24 & Tumoração não ulcerada & Pos. & Pos. & $\begin{array}{l}\text { Necrose eosinofílica com hifas } \\
\text { irregulares e ramificadas }\end{array}$ \\
\hline II / 03 & 8 & $\mathrm{~F}^{\mathrm{b}}$ & Peito & $46 \times 32$ & 12 & $\begin{array}{l}\text { Tumoração não ulcerada, } \\
\text { pedunculada }\end{array}$ & Pos. & Pos. & $\begin{array}{l}\text { Necrose eosinofílica com hifas } \\
\text { irregulares e ramificadas }\end{array}$ \\
\hline II / 04 & 8 & $\mathrm{~F}$ & MAE & $\begin{array}{c}15 \times 67 \\
\text { diâmetro }\end{array}$ & 12 & Tumoração não ulcerada & Pos. & Neg. & Biópsia sem kunkers \\
\hline II / 05 & 6 & $\mathrm{~F}$ & MPD & $30 \times 18$ & 24 & $\begin{array}{l}\text { Tumoração não ulcerada } \\
\text { irregulares e ramificadas }\end{array}$ & Pos. & Pos. & Necrose eosinofílica com hifas \\
\hline II / 06 & 3 & $\mathrm{~F}$ & Peito & $19 \times 23$ & 18 & $\begin{array}{l}\text { Tumoração não ulcerada, } \\
\text { pedunculada }\end{array}$ & Pos. & Pos. & Biópsia sem kunkers \\
\hline
\end{tabular}

${ }^{\mathrm{a}} \mathrm{MAD}=$ membro anterior direito, $\mathrm{MPD}=$ membro posterior direito, $\mathrm{MAE}=$ membro anterior esquerdo, $\mathrm{MPE}=$ membro posterior esquerdo, Pos. $=$ positivo, Neg. = negativo,

b= égua com cria ao pé. 

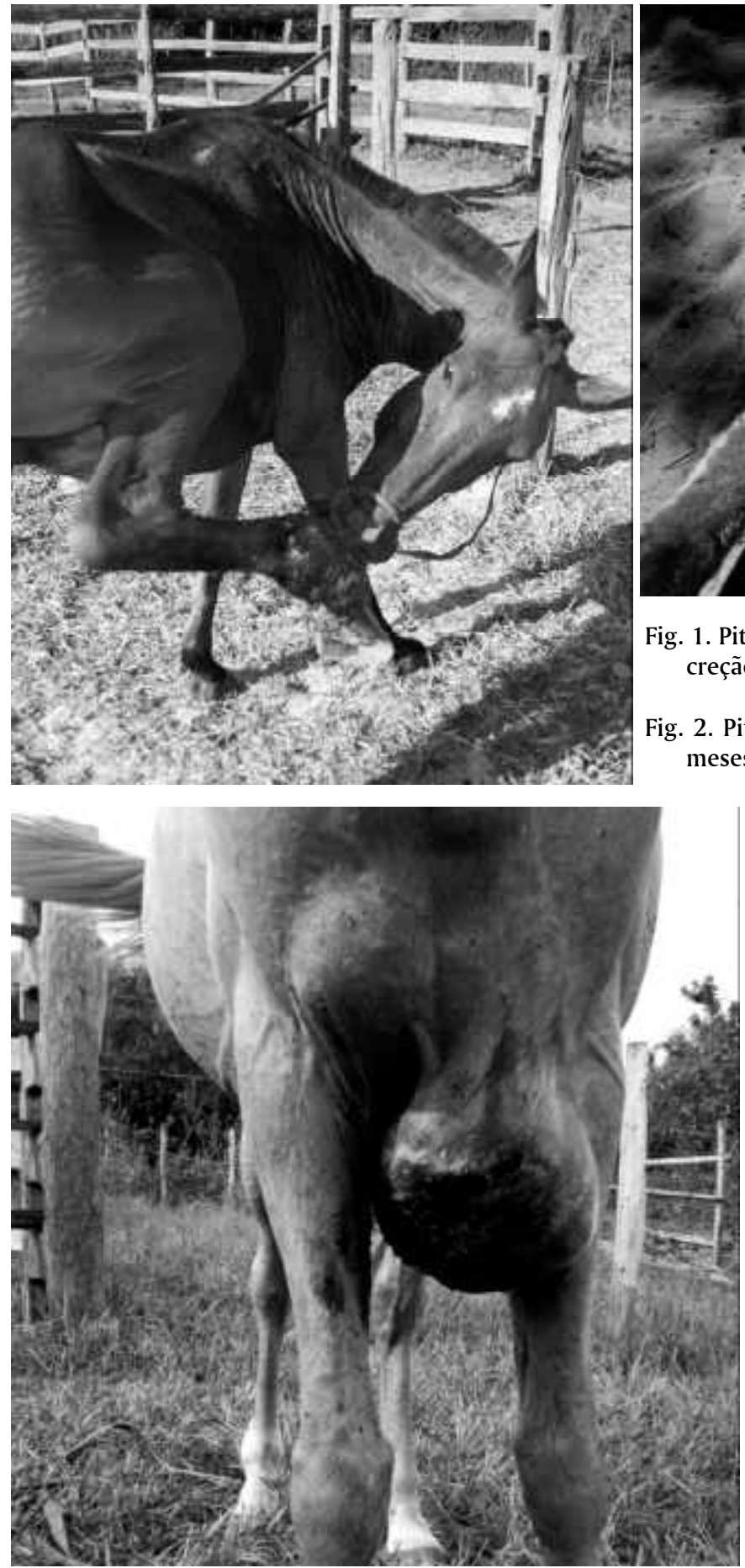

Fig. 3. Pitiose eqüina atípica (Eqüino 3). Égua em lactação, com cria ao pé e bom estado geral, apresentando lesão circunscrita e pedunculada. Duração superior a 12 meses.

cinco eqüinos. Na histopatologia, observou-se proliferação de tecido de granulação com muitos eosinófilos na derme superficial e profunda, às vezes acompanhado de hiperplasia irregular da epiderme. Associados aos "kunkers", foram observadas imagens negativas de hifas irregulares e ramificadas.
Quadro 2. Principais diferenças entre os casos típicos (Grupo I) e atípicos (Grupo II) de pitiose em eqüinos

\begin{tabular}{lcc}
\hline $\begin{array}{l}\text { Características } \\
\text { das lesões }\end{array}$ & $\begin{array}{c}\text { Grupo I } \\
\text { (1 a 6 meses })\end{array}$ & $\begin{array}{c}\text { Grupo II } \\
(>12 \text { meses })\end{array}$ \\
\hline $\begin{array}{l}\text { Ulceração } \\
\begin{array}{l}\text { Secreção } \\
\text { Prurido }\end{array}\end{array}$ & $\begin{array}{c}\text { Presente } \\
\text { Abundante } \\
\text { Histopatologia }\end{array}$ & $\begin{array}{c}\text { Ausente } \\
\text { Pouca }\end{array}$ \\
& $\begin{array}{c}\text { Presente } \\
\text { Tecido de granulação } \\
\text { com muitos eosinófilos }\end{array}$ & $\begin{array}{c}\text { Ausente } \\
\text { Hiperplasia pseudo-epitelio- } \\
\text { matosa da epiderme e infil- }\end{array}$
\end{tabular}
trado eosinofílico

${ }^{\mathrm{a}}$ Lesões recobertas por pele escura

Pelo método de Gömori (GMS) foram observadas hifas irregulares e ramificadas no centro ou na periferia dos "kunkers".

No Grupo II (casos atípicos), foram incluídos cinco eqüinos com duração da doença superior a 12 meses e quadro clínico estável, incluindo bom estado nutricional. As lesões subcutâneas caracterizavam-se por grandes massas teciduais recobertas por pele hiperpigmentada, eventualmente com pêlos, sem ulcerações e presença de alguns pontos abertos (sinus) com a drenagem de pouca secreção serossanguinolenta e fragmentos de "kunkers" (Fig. 2). O prurido estava ausente ou foi raramente observado. Em alguns casos, as tumorações apresentavam-se bastante circunscritas, pedunculadas e com tamanho estável (Fig. 3). Histologicamente, esses casos caracterizaram-se por hiperplasia pseudo-epiteliomatosa da epiderme e hiperplasia das glândulas sebáceas, às vezes com hiperqueratose ortoqueratótica. Infiltrado focal ou difuso de polimorfonucleares com muitos eosinófilos e, em alguns casos, proliferação de tecido de granulação maduro também foram observados. Hifas irregulares e ramificadas foram observadas no centro e na periferia dos "kunkers". 


\section{DISCUSSÃO}

A pitiose eqüina é uma doença que ocorre em todas as regiões do Brasil, principalmente no Pantanal, onde há relação direta com o período das chuvas (outubro-março) e acarreta prejuízos significativos, direta ou indiretamente. Os casos de pitiose cutânea/subcutânea descritos na literatura e também observados nos casos típicos apresentados nesse trabalho, caracterizam-se por granulomas ulcerados com abundante secreção serossanguinolenta, prurido intenso e presença de "kunkers" visíveis na superfície e interior da ferida (Meireles et al. 1993, Chaffin et al. 1995, Tabosa et al. 1999). A evolução dessa forma clínica é rápida, acompanhada de aumento progressivo das lesões, emagrecimento e debilidade, culminando com a morte na maioria dos casos. Infecções secundárias são freqüentemente observadas e representam uma dificuldade adicional para o isolamento do agente e tratamento da doença. Em geral, lesões muito ulceradas e com secreção abundante apresentam alto grau de contaminação secundária. Acredita-se que a morte esteja associada à liberação de fatores de necrose tumoral - TNF $\alpha$. Esses são liberados em processos tumorais ou infecções por bactérias Gram negativas ou outros agentes que possuam lipopolissacarídeos de parede (LPS) e, são os responsáveis pelo fenômeno de caquexia observados em humanos e animais com essas enfermidades (Klein \& Horejsi 1997).

Os casos atípicos descritos no presente trabalho destacaram-se pelo curso clínico prolongado (superior a 1 ano) e pelos aspectos clínicos peculiares. Ao contrário da pitiose típica, os equiinos com pitiose atípica aparentavam boa saúde geral, sem comprometimento de suas funções vitais. A presença de uma égua com cria ao pé comprova que a infecção atípica não prejudicou funções como a gestação e a lactação. As lesões subcutâneas caracterizavam-se por grandes tumorações, que em alguns casos apresentavam-se pedunculadas (Fig. 3), sugerindo uma organização tecidual com isolamento da área infectada. Os sinais clínicos geralmente observados, como prurido, secreção abundante e emagrecimento progressivo, também estavam ausentes. Histologicamente, as massas tumorais caracterizavam-se por hiperplasia pseudo-epitelio-matosa da epiderme. Essa característica histológica também é observada nos casos de sarcóide equiino e pode indicar uma associação entre as duas patologias, onde um sarcóide ulcerado seria a "porta de entrada" para Pythium insidiosum. Entretanto, não há dados que confirmem essa possibilidade.

O longo período de infecção e as características teciduais da lesão são indícios de que os equiinos do Grupo II conseguiram controlar a infecção, evitando o quadro clássico de evolução progressiva e morte. Porém, a presença de "kunkers" viáveis no interior das lesões sugere que o sistema imunológico conseguiu apenas isolar a área infectada sem eliminar o agente infeccioso. Também não se sabe qual seria a evolução natural desses casos, se para a cura ou para a morte desses animais. $\mathrm{O}$ acompanhamento da evolução natural foi prejudicado pelo uso da imunoterapia, que induziu a cura em quatro animais. No eqüino que não respondeu a imunoterapia, a doença culminou com a morte do animal, porém a observa- ção de apenas um animal não permite afirmar que a evolução natural de todos os casos atípicos seria à morte. Todos os equïnos apresentados nesse relato fizeram parte de um teste de eficiência de um imunobiológico para o tratamento da pitiose eqüina, produzido a partir de culturas de $P$. insidiosum (Dados não publicados).

Dos cinco eqüinos com pitiose atípica, três já haviam apresentado outros episódios da doença em anos anteriores, sendo curados pelo "corte e queima" das lesões (tratamento caseiro). A possibilidade de recidiva foi descartada, pois as lesões observadas foram em locais diferentes da primeira infeç̧ão. A ocorrência desses casos levanta suspeitas sobre a influência das infecções anteriores sobre a imunidade a reinfecções. Entretanto isso não foi relatado em dois dos casos atípicos e não há estudos sistemáticos que permitam afirmar que animais previamente infectados desenvolvam algum grau de imunidade ao P. insidiosum. Por outro lado, a ocorrência desses casos pode estar relacionada a diferenças individuais na susceptibilidade e resistência à doença. Em humanos, a talassemia é um fator predisponente para o desenvolvimento da pitiose, embora indivíduos normais também possam ser infectados (Sathapatayavongs et al. 1989, Imwidthaya 1994). Em equiinos, até o presente, não foi descoberto nenhum fator que predisponha à infecção porP. insidiosum. Outra possível causa de variações na apresentação clínica da doença é a existência de diferenças antigênicas entre isolados de $P$. insidiosum. Isso tem sido observado em nossos estudos de comparação antigênica (Dados não publicados).

Casos de pitiose eqüina atípica ainda não foram descritos na literatura e representam um importante achado no estudo da pitiose, pois o entendimento de suas causas e mecanismos envolvidos podem esclarecer outros aspectos na patogenia e no controle da enfermidade.

\section{REFERÊNCIAS}

Alexopoulos C. J., Mims C. W. \& Blackwell M. 1996. Phylum Oomycota, p. 683737. In: Introductory Mycology. 4th ed. John Wiley \& Sons, New York.

Alfaro A.A. \& Mendoza L. 1990. Four cases of equine bone lesions caused by Pythium insidiosum. Eq. Vet. J. 22(4):295-297.

Allison N. \& Gillis J.P. 1990. Enteric pythiosis in a horse. J. Am. Vet. Med. Assoc. 196(3):462-464.

Bissonnete K.W., Sharp N.J.H., Dykstra M.H., Robertson I.R., Davis B., Padhye A.A. \& Kaufman L. 1991. Nasal and retrobulbar mass in a cat caused by Pythium insidiosum. J. Med. Vet. Mycol. 29:39-44.

Carvalho E.C.Q., Rosa C.A.R.R., Cruz L.C.H. \& Scaff, R.M. 1984. "Hyphomyces destruens": agente da "ferida brava" (hifomicose) em eqüinos do Pantanal de MT. Anais XIX Congr. Bras. Med. Vet., Cuiabá, p. 311. (Resumo)

Chaffin M.K., Schumacher J. \& McMullan W.C. 1995. Cutaneous pythiosis in the horse. Vet. Clin. North Am. Eq. Pract. 11(1):91-103.

Dykstra M.J., Sharp N.J.H., Olivry T., Hillier A., Murphy K.M., Kaufman L., Kunkle G.A. \& Pucheu-Haston, C. 1999. A description of cutaneous-subcutaneous pythiosis in fifteen dogs. Med. Mycol. 37:427-433.

Eaton S. 1993. Osseous involvement by Pythium insidiosum. Comp. Cont. Educ. Pract. Veter. 15(3):485-488.

Fischer J.R., Pace L.W., Turk J.R., Kreeger J.M., Miller M.A. \& Gosser, H.S. 1994 Gastrointestinal pythiosis in Missouri dogs: eleven cases. J. Vet. Diagn. Invest. 6:380-382.

Imwidthaya P. 1994. Human pythiosis in Thailand. Postgrad. Med. J. 70:558 560 . 
Klein J. \& Horejsi V. 1997. Cytokines and their receptors, p. 291-326. In: Immunology. 2nd ed. Blackwell Science, London.

Leal A.T., Leal A.B.M., Flores E.F \&.Santurio J.M. 2001. Pitiose. Ciência Rural 31(4):735-743.

Meireles M.C., Riet-Correa F., Fischman O., Zambrano A.F.H. \& Ribeiro, G.A. 1993. Cutaneous pythiosis in horses from Brazil. Mycoses 36:139-142.

Mendoza L. \& Prendas J. 1988. A method to obtain zoosporogenesis of Pythium insidiosum. Mycopathologia 6:5-12.

Mendoza L., Ajello L. \& McGinnis M. R. 1996. Infections caused by the oomycetous pathogen Pythium insidiosum. J. Mycol. Med. 6(4):151-164.

Miller R.I. \& Campbell R. S.F. 1982. Clinical observations on equine phycomycosis. Aust. Vet. J. 58: 221-226.

Miller R.I. \& Campbell R.S.F. 1984. The comparative pathology of equine cutaneous phycomycosis. Vet. Pathol. 21:325-332.

Miller R.I., Olcott B.M. \& Archer, M. 1985. Cutaneous pythiosis in beef calves. J. Am. Vet. Med. Assoc. 186(9):984-986.

Morton L.D., Morton D.G., Baker G.J. \& Gelberg H.B. 1991. Chronic eosinophilic enteritis attributed to Pythium sp. in a horse. Vet. Pathol. 28:542-544.
Sanavria A., Fabris V.E., Campos S.G., Peixoto P.F.V., Morais M.C. \& Fernandes C.G.N. 2000. Pitiose em eqüinos: relato de cinco casos no estado do Rio de Janeiro. Revta Bras. Med. Vet. 22(4):170-173.

Santos M.N. \& Londero A.T. 1974. Zigomicose subcutânea em cavalos. Pesq. Agropec. Bras., Sér. Vet. 9:7-8.

Santurio J.M., Monteiro A.B., Leal A.T., Kommers G.D., Sousa R.S. \& Catto J.B. 1998. Cutaneous Pythiosis insidiosi in calves from the Pantanal region of Brazil. Mycopathologia 141:123-125.

Sathapatayavongs B., Leelachaikul P., Prachaktam R., Atichartakarn V., Sriphojanart S., Trairatvorakul P., Jirasiritham S., Nontasut S., Eurvilaichit C. \& Flegel T. 1989. Human pythiosis associated with thalassemia hemoglobinopathy syndrome. J. Infect. Dis. 159(2):274-280.

Shipton W.A., Miller R.I. \& Lea I.R. 1982. Cell wall, zoospore and morphological characteristics of Australian isolates of a Pythium causing equine phycomycosis. Trans. Brit. Mycol. Soc. 79(1):15-23.

Tabosa I.M., Medeiros V.T., Dantas A.F.M., Azevedo E.O. \& Maia J.C. 1999. Pitiose cutânea em eqüinos no semi-árido da Paraíba. Arq. Bras. Med. Vet. Zootec. 51(1): 27-30. 